\title{
EFEKTIVITAS GROUP BEHAVIOR THERAPY TERHADAP CONVERSATIONAL SKILL PADA PASIEN SKIZOFRENIA TIPE RESIDUAL (STUDI KASUS PADA INSTANSI X)
}

\author{
Garvin \\ Program Studi Psikologi Universitas Bunda Mulia \\ garvin.goei@gmail.com
}

\begin{abstract}
Schizophrenia residual type is one of schizophrenia types which is the symptoms of schizophrenia are no longer appears significantly. The schizophrenia patients are need to be prepared before they complete their treatment in a mental health institution and back into society. A skill that is needed by schizophrenia residual type is conversational skills. However, some of schizophrenia patients are encountering problems in learning the conversational skills. The aim of this research is to study the effectiveness of group behavior therapy into the conversational skills of schizophrenia residual type patients. The technique used in the therapy is modeling and shaping. Statistical test with significance $p=0,002<0,01$ shows that group behavior therapy can improve conversational skills in schizophrenia residual type patients. However, there are some limitations in the study so further study is needed.
\end{abstract}

Keywords: schizophrenia residual type; conversational skill; group behavior therapy

\begin{abstract}
ABSTRAK
Schizophrenia tipe residual merupakan salah satu tipe gangguan schizophrenia di mana simtom-simtom dari schizophrenia tidak lagi muncul secara signifikan. Sebelum pasien schizophrenia selesai menjalani perawatan dalam instansi kesehatan jiwa dan kembali ke dalam masyarakat, pasien schizophrenia perlu dipersiapkan terlebih dahulu. Salah satu keterampilan yang dibutuhkan oleh pasien schizophrenia tipe residual adalah conversational skill. Namun, tak jarang pasien schizophrenia tipe residual menemui permasalahan dalam memelajari conversational skill. Penelitian ini bertujuan untuk mengetahui efektivitas dari group behavior therapy terhadap conversational skill dari pasien schizophrenia tipe residual. Teknik yang digunakan dalam terapi adalah modeling dan shaping. Hasil pengujian statistik dengan signifikansi $\mathrm{p}=0,002<0,01$ menemukan bahwa group behavior therapy dapat meningkatkan conversational skill pada pasien schizophrenia tipe residual. Meski demikian, terdapat beberapa keterbatasan dalam penelitian sehingga masih diperlukan studi lebih lanjut.
\end{abstract}

Kata kunci: skizofrenia tipe residual; conversational skill; group behavior therapy

\section{PENDAHULUAN}

\subsection{Latar Belakang}

Schizophrenia merupakan gangguan mental yang serius dan berpeluang terjadi pada siapa saja (Hafner \& Heiden, 1997; McGrath, Saha, Chant, Welham, 2008). Hasil riset menyatakan bahwa 4 hingga 7 orang dari 1000 orang menyandang schizophrenia (Saha, Chant, Welham, McGrath; 2005). Data dari World Health Organization atau WHO menyatakan bahwa schizophrenia sudah disandang oleh lebih dari 21 juta orang di seluruh dunia. Sedangkan bererdasarkan National Institute of Mental Health (NIMH, 2011), sekitar $1,1 \%$ dari populasi di dunia mengalami schizophrenia.

Pasien schizophrenia biasanya akan menjalani perawatan di rumah sakit jiwa yang terdiri dari rehabilitasi. Setelah menjalani rehabilitasi, diharapkan pasien schizophrenia mengalami peningkatan keberfungsian sosial dan perilaku, seiring dengan peningkatan kualitas hidupnya (Sellwood et al., 1999).

Menurut Bellack, Mueser, Gingerich, dan Agresta (2004), 
conversational skill merupakan hal yang sulit oleh dilakukan bagi para penderita schizophrenia. Padahal, conversational skill merupakan bagian dari social skill yang diperlukan oleh pasien schizophrenia yang sudah pulih dan akan kembali ke lingkungan. Pelatihan social skill dibutuhkan bagi pasien schizophrenia yang akan segera kembali ke lingkungan untuk mampu mendiskusikan pengobatan dengan psikiater, memesan makanan di restoran, mengisi aplikasi pekerjaan, menjalani wawancara pekerjaan, menolak tawaran obat-obatan terlarang di jalan, dan membaca jadwal kendaraan umum (Kring, Johnson, Davison, Neale; 2010). Orang dengan schizophrenia memerlukan usaha untuk mendapatkan keterampilan tersebut sehingga butuh mendapatkan pelatihan social skill, yang salah satunya adalah conversational skill (Kring et al., 2010).

Heinssen, Liberman, dan Kopelowicz (2000) berpendapat bahwa penanganan schizophrenia secara psikofarmaka efektif untuk mengatasi halusinasi dan delusi, namun kurang efektif untuk mengatasi kurangnya keterampilan sosial, yang salah satunya adalah conversational skill. Intervensi dengan pendekatan psikososial adalah metode yang dianggap berperan dalam pemulihan keberfungsian pasien. Menurut Padmavathi, Lalitha, dan Parthasarathy (2013), role play merupakan salah satu metode yang efektif untuk melatih conversational skill pada pasien schizophrenia.

Instansi X yang berada di Jakarta memberikan layanan rehabilitasi bagi pasien schizophrenia yang telah menjalani rawat inap maupun rawat jalan, sehingga pasien bisa dipersiapkan dengan baik sebelum benar-benar dikembalikan kepada masyarakat. Dalam program rehabilitasi tersebut, pasien schizophrenia yang sebagian besar merupakan tipe residual mendapatkan berbagai macam pembekalan, seperti pelatihan vokasional, okupasional, pelatihan psikomotorik, hingga bimbingan rohani. Menurut salah satu kepala perawat di sana, faktor yang menghambat kemajuan pasien dalam menjalani rehabilitasi adalah conversational skill. Tanpa conversational skill, pasien hanya datang untuk mengikuti program pelatihan vokasional, okupasional, maupun bimbingan rohani; padahal mereka juga membutuhkan komunikasi interpersonal agar bisa saling mendukung satu sama lain dalam penyembuhan. Selain itu, tidak adanya program pelatihan conversational skill membuat mereka kurang aktif dalam bercakap-cakap satu sama lain (Komunikasi Personal, 1 Juni -8 Juni 2015). Oleh karena itu, dibutuhkan pelatihan conversational skill bagi pasien schizophrenia tipe residual yang sedang menjalani rehabilitasi di instansi $X$. Berdasarkan informasi-informasi di atas, maka peneliti bermaksud untuk meneliti penerapan group behavior therapy untuk meningkatkan conversational skill pada pasien schizophrenia tipe residual di instansi $\mathrm{X}$.

\subsection{Tujuan Penelitian}

Penelitian ini bertujuan untuk mengetahui efektivitas penerapan group behavior therapy terhadap conversational skill pada pasien schizophrenia tipe residual.

\section{TINJAUAN PUSTAKA \\ 2.1 Schizophrenia}

Schizophrenia merupakan gangguan dengan jangkauan gejala yang meliputi gangguan terhadap isi pemikiran, bentuk pemikiran, persepsi, afeksi, sense of self, motivasi, perilaku, dan keberfungsian interpersonal (Halgin \& Whitbourne, 2009). Strauss et al (dalam Arif, 2006) menyatakan bahwa schizophrenia merupakan gangguan mental yang sangat berat, ditandai dengan gejala-gejala positif seperti pembicaraan yang kacau, delusi, halusinasi, gangguan kognitif dan persepsi; serta gejala-gejala negatif seperti menurunnya minat dan dorongan, berkurangnya keinginan bicara dan miskinnya isi pembicaraan, afek yang datar, serta terganggunya relasi personal. Bila tidak mendapatkan penanganan, keberfungsian dari penderita schizophrenia dapat terganggu dengan berat.

Schizophrenia memiliki 2 simtom utama, yakni simtom positif dan simtom negatif. Simtom positif dari schizophrenia adalah delusi dan halusinasi, sedangkan simtom negatif dari schizophrenia adalah avolition, alogia, anhedonia, dan flat affect 
(Kring, Johnson, Davison, Neale; 2012). Simtom-simtom negatif yang muncul pada penderita schizophrenia membuat seseorang menjadi menarik diri dan tidak terlibat dalam komunikasi interpersonal. Misalnya seperti alogia, yakni hilangnya ketertarikan untuk berbicara dengan orang lain atau flact affect, yakni ketidakmampuan seseorang untuk menunjukkan emosinya (Barlow \& Durand, 2012).

Schizophrenia pun terbagi ke dalam beberapa jenis, yakni (a) paranoid, (b) disorganized, (c) katatonik, (d) undifferentiated, dan (e) residual (Barlow \& Durand, 2012; Kring, Johnson, Davison, Neale; 2012). Individu yang sudah memiliki setidaknya satu episode dari schizophrenia tapi tidak lagi menunjukkan simtom-simtom umum didiagnosa sebagai schizophrenia tipe residual. Individu yang sudah didiagnosa sebagai tipe residual tidak lagi menunjukkan keanehan karena delusi maupun halusinasi, tapi masih menunjukkan beberapa simtom yang bersifat sisaan, seperti penarikan diri secara sosial, flat affect, maupun pemikiran aneh (Barlow \& Durand, 2012; Kring et al, 2012).

\begin{tabular}{|c|}
\hline \\
\hline \\
\hline \\
\hline \\
\hline \\
\hline \\
\hline \\
\hline \\
\hline \\
\hline \\
\hline 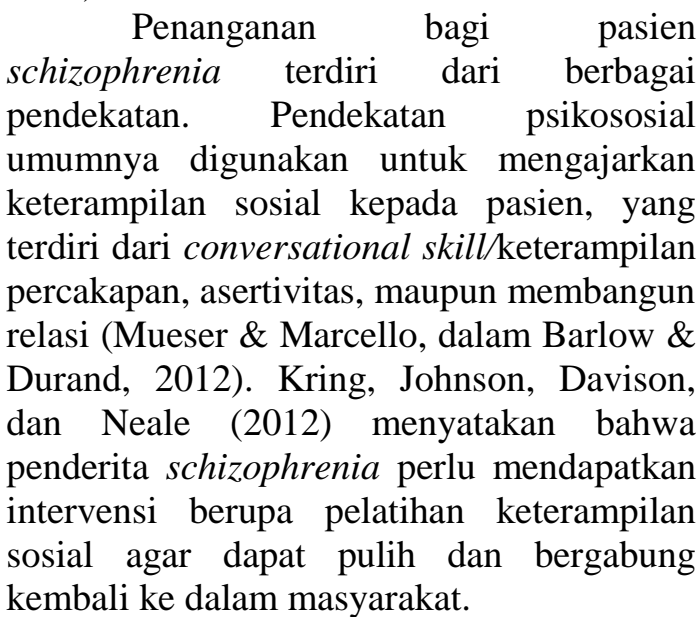 \\
\hline
\end{tabular}

\subsection{Conversational Skill}

Bellack, Gingerich, dan Agresta (2004) menyatakan ada tujuh komponen dalam conversational skill, yakni: (1) kontak mata saat berbicara, (2) memulai percakapan dengan orang lain, (3) menjaga percakapan dengan bertanya, (4) menjaga percakapan dengan memberikan informasi faktual, (5) menjaga percakapan dengan mengekspresikan pertanyaan, (6) mengakhiri pembicaraan, dan (7) mengikuti topik pembicaraan yang sudah ditentukan oleh orang lain. Sedangkan menurut Padmavathi, Lalitha, \& Parthasarathy (2013), conversational skill terdiri dari area, antara lain: (1) memulai pembicaraan dengan orang asing, (2) mempertahankan pembicaraan dan bertanya, (3) mempertahankan pembicaraan dengan memberikan informasi faktual, (4) mempertahankan pembicaraan dengan mengekspresikan perasaan, (5) mengakhiri pembicaraan, (6) bergabung dalam sebuah percakapan, (7) mengikuti topik yang ditentukan oleh lain, (8) tindakan yang harus dilakukan apabila ada yang mengubah topik, (9) menyatakan pendapat, dan (10) yang harus dilakukan apabila seseorang tidak memahami ucapan subyek.

\subsection{Behavior therapy}

Pendekatan behavioral sudah sejak lama digunakan sebagai teknik psikoterapi pada kasus-kasus psikologis, termasuk schizophrenia. Dalam pendekatan behavioral, ada beberapa teknik yang digunakan, beberapa di antaranya adalah modeling dan operant conditioning. Modeling atau observational learning merupakan proses pembelajaran melalui pengamatan terhadap fenomena di sekitar (Feis, Feist, \& Roberts; 2013). Bandura (dalam Feist, Feist, \& Roberts, 2013; Trull, 2013) menyatakan bahwa modeling lebih efektif dalam pembelajaran dibandingkan operant conditioning. Meski demikian, secara praktis, modeling dan operant conditioning seringkali digunakan secara bersamaan untuk meningkatkan efektivitas pembelajaran. Thorpe dan Olson (dalam Trull, 2013) menyatakan bahwa modeling efektif dan efisien bila keempat kondisi berikut dipenuhi: (a) pasien benar-benar memperhatikan model, terkadang insentif diperlukan untuk membantu atensi klien, (b) pasien mendapatkan informasi yang disediakan oleh model, (c) pasien harus melakukan perilaku yang dimodel, (d) pasien harus memiliki motivasi untuk melakukan perilaku yang sudah dimodel menggunakan reinforcement. Keempat syarat tersebut menunjukkan bahwa modeling akan lebih efektif bila reinforcement juga dilibatkan dalam proses 
pembelajaran, yang merupakan bagian dari operant conditioning.

Operant conditioning merupakan metode modifikasi perilaku dengan menggunakan reinforcement atau penguat dan hukuman. Operant conditioning memodifikasi perilaku seseorang melalui konsekuensi dari sebuah perilaku (Trull, 2013). Misalnya, untuk meningkatkan perilaku yang diharapkan, maka terapis perlu memberikan reinforcement atau penguat; sebaliknya, untuk mengurangi munculnya perilaku yang tidak diharapkan, maka terapis perlu memberikan punishment atau hukuman (Feist, Feist, \& Roberts; 2013). Salah satu teknik yang menggunakan prinsip operant conditioning adalah shaping, yaitu memberikan penghargaan/reward terhadap perilaku yang diharapkan (Trull, 2013)

\section{METODE PENELITIAN}

Subyek dalam penelitian ini adalah pasien schizophrenia tipe residual yang sedang menjalani program rehabilitasi di Instansi X, Jakarta. Teknik sampling yang digunakan adalah convenient sampling, karena keterbatasan jumlah subyek. Kriteria pemilihan subyek adalah: (1) penyandang schizophrenia tipe residual, (2) sedang menjalani program rehabilitasi di Instansi X, dan (3) memiliki masalah dalam conversational skills. Peneliti tidak membatasi subyek berdasarkan usia dengan pertimbangan keterbatasan jumlah pasien yang sedang menjalani rehabilitasi dan memiliki masalah dalam conversational skills di sana. Sebelum penelitian dilaksanakan, peneliti sudah melakukan rapport building dan melakukan pemeriksaan psikologis, kemudian meminta kesediaan subyek untuk mengikuti intervensi. Berdasarkan kriteria-kriteria di atas, subyek yang terlibat dalam penelitian ini berjumlah lima orang, dengan perincian sebagai berikut:

Tabel 1: Subyek Penelitian

\begin{tabular}{ccc}
\hline Inisial & Usia & Jenis Kelamin \\
\hline HW & 21 tahun & Laki-laki \\
APN & 31 tahun & Laki-laki \\
RD & 19 tahun & Laki-laki \\
CH & 24 tahun & Laki-laki \\
AR & 43 tahun & Laki-laki \\
\hline
\end{tabular}

Penelitian berlangsung dalam beberapa tahap. Pertama, peneliti melakukan pre-test terlebih dahulu kepada kelima subyek. Pre-test ini dilaksanakan agar peneliti bisa memeroleh baseline dari conversational skills subyek. Pre-test dilakukan melalui observasi yang dilakukan oleh peneliti. Panduan observasi berupa checklist, menggunakan kriteria conversational skills yang disebutkan oleh Bellack, Mueser, Gingerich, dan Agresta (2004).

Tahap kedua, peneliti melaksanakan intervensi dengan basis behavioral kepada keenam subyek. Sesi intervensi dilakukan selama 1 bulan, terdiri dari 7 sesi pertemuan. Peneliti menggunakan pendekatan behavioral sebagai basis pelatihan dengan menggunakan teknik role-playing, behavior modification, dan modeling. Menurut Bandura (dalam Heinssen, Liberman, \& Kopelowicz, 2000), prosedur pelatihan keterampilan yang bersifat psikososial berakar pada operant conditioning (reward dan punishment) dan social learning theory. Para subyek akan diarahkan untuk saling berbincang dan mendukung satu sama lain agar conversational skill mereka dapat terlatih.

Pertama-tama, subyek akan melakukan modeling, diawali oleh peneliti yang akan memberikan contoh aktivitas berbincang terlebih dahulu bersama rekan dari peneliti, kemudian diikuti oleh subyek yang berpasangan dalam kelompok. Tujuan dari pemberian contoh adalah agar keenam subyek mampu memelajari conversational skill langsung melalui modeling, sesuai dengan Bellack, Mueser, Gingerich, dan Agresta (2004) yang menyatakan bahwa conversational skill mampu diajarkan 
melalui social learning yang terdiri dari observasi dan modeling.

Setelah mengamati dan melakukan modeling terhadap peneliti dan rekan peneliti yang mencontohkan cara untuk melakukan percakapan, subyek pun selanjutnya diminta untuk melakukan role play. Subyek akan berpasangan dan melakukan percakapan sesuai dengan topik yang sudah ditentukan oleh peneliti. Subyek yang berhasil melakukan percakapan dengan lancar akan mendapatkan reward berupa pujian dari peneliti dan subyek lainnya, dengan harapan bisa menjadi positive reinforcement bagi subyek yang berhasil. Dalam behavior therapy, metode ini disebut sebagai shaping. Bila subyek belum berhasil melakukan percakapan dengan lancar, peneliti akan mencontohkan ulang percakapan dengan rekan peneliti, sehingga subyek yang belum berhasil tersebut dapat melakukan modeling kembali.

Tabel 2: Rancangan Sesi Intervensi

\begin{tabular}{lll}
\hline Sesi & Tujuan sesi & $\begin{array}{c}\text { Teknik yang } \\
\text { Digunakan }\end{array}$
\end{tabular}

\begin{tabular}{lll}
\hline 1 & $\begin{array}{l}\text { Kontak mata saat } \\
\text { berbicara \& } \\
\text { memulai } \\
\text { percakapan dengan } \\
\text { orang lain }\end{array}$ & $\begin{array}{l}\text { Modeling \& } \\
\text { Shaping }\end{array}$ \\
\hline 2 & $\begin{array}{l}\text { Menjaga } \\
\text { percakapan dengan } \\
\text { bertanya }\end{array}$ & $\begin{array}{l}\text { Modeling \& } \\
\text { Shaping }\end{array}$ \\
\hline 3 & $\begin{array}{l}\text { Menjaga } \\
\text { percakapan dengan } \\
\text { memberikan } \\
\text { informasi faktual }\end{array}$ & $\begin{array}{l}\text { Modeling \& } \\
\text { Shaping }\end{array}$ \\
\hline 4 & $\begin{array}{l}\text { Menjaga } \\
\text { percakapan dengan } \\
\text { mengekspresikan } \\
\text { perasaan }\end{array}$ & $\begin{array}{l}\text { Modeling \& } \\
\text { Shaping }\end{array}$ \\
\hline 5 & $\begin{array}{l}\text { Mengakhiri } \\
\text { pembicaraan } \\
\text { dengan orang lain }\end{array}$ & $\begin{array}{l}\text { Modeling \& } \\
\text { Shaping }\end{array}$ \\
\hline 6 & $\begin{array}{l}\text { Mengikuti topik } \\
\text { pembicaraan yang } \\
\text { sudah ditentukan }\end{array}$ & $\begin{array}{l}\text { Modeling \& } \\
\text { Shaping }\end{array}$ \\
\hline & & \\
\hline
\end{tabular}

\begin{tabular}{lll}
\hline \multicolumn{3}{c}{ oleh orang lain } \\
\hline 7 & $\begin{array}{l}\text { Review dan } \\
\text { terminasi }\end{array}$ & $\begin{array}{l}\text { Modeling \& } \\
\text { Shaping }\end{array}$ \\
\hline
\end{tabular}

Terakhir, pada tahap ketiga, peneliti melakukan post-test, dengan jeda waktu 1 minggu setelah seluruh rangkaian proses terapi selesai. Sama seperti pre-test, post-test dilakukan melalui observasi, dilaksanakan oleh peneliti dengan panduan observasi berupa checklist menggunakan kriteria conversational skill dari Bellack, Mueser, Gingerich, dan Agresta (2004).

\section{HASIL DAN PEMBAHASAN}

Sebelum memberikan intervensi, peneliti menyusun baseline dari conversational skill keenam subyek, menggunakan metode observasi dengan panduan yang sudah disusun berdasarkan konsep conversational skill dari Bellack, Mueser, Gingerich, dan Agresta (2004). Observasi dilakukan di institusi $\mathrm{X}$ dengan menggunakan rating recording, dengan kriteria penilaian angka 1 yang berarti sangat kurang, 2 berarti kurang, 3 berarti cukup, 4 berarti baik, dan 5 yang berarti sangat baik. Observasi dilakukan sebanyak dua kali, yakni sebelum intervensi dan sesudah intervensi.

Skor reliabilitas dari observasi dihitung menggunakan rating recording percentage agreement estimate, dengan skor sebesar 0,77 atau $77 \%$. Hasil observasi pada komponen conversational skill yang pertama, yakni "kontak mata", mendapatkan skor minimal 1 dan maksimal 3, dengan mean empiris 1,6 dan mean hipotetis 2. Skor mean empiris lebih kecil dibandingkan mean hipotetis, maka dapat disimpulkan bahwa kontak mata dari kelima partisipan sebelum menjalani intervensi tergolong rendah.

Hasil observasi pada komponen kedua, yaitu "memulai percakapan dengan orang lain", memeroleh skor minimal 1 dan skor maksimal 1,5; dengan mean empiris 1,1 dan mean hipotetis 2. Berdasarkan data tersebut, peneliti menyimpulkan bahwa kelima partisipan memiliki kemampuan memulai percakapan yang tergolong rendah, sebelum menjalani intervensi. 
Hasil observasi pada komponen ketiga, yaitu "menjaga percakapan dengan bertanya", menghasilkan skor minimal 1 dan skor maksimal 2, dengan skor mean empiris 1,3 dan mean hipotetis 3. Skor mean hipotetis yang lebih besar dari skor mean empiris menunjukkan bahwa kelima partisipan memiliki kemampuan menjaga percakapan melalui bertanya yang tergolong rendah.

Pada komponen keempat dari conversational skill, yakni "menjaga percakapan dengan memberikan informasi faktual", kelima subyek menunjukkan skor minimal 1 dan skor maksimal 1,5; dengan mean empiris 1,1 dengan skor mean hipotetis 3. Hal ini menunjukkan bahwa kelima partisipan memiliki kemampuan yang tergolong rendah untuk menjaga percakapan dengan memberikan informasi faktual, sebelum menjalani intervensi.

Komponen kelima dari conversational skill, yakni "menjaga percakapan dengan mengekspresikan perasaan", menghasilkan skor minimal 1 dan skor maksimal 1,5. Skor mean empiris 1,1 dan mean hipotetis 3, hal ini berarti kemampuan kelima partisipan untuk menjaga percakapan dengan mengekspresikan pertanyaan tergolong rendah.

Komponen keenam dari conversational skill, yakni "mengakhiri percakapan", menghasilkan skor minimal 1 dan maksimal 1, dengan skor mean empiris 1. Hasil skor mean empiris yang lebih rendah dari skor mean hipotetis menunjukkan bahwa skor kelima partisipan pada komponen keenam masih tergolong rendah.

Komponen ketujuh dari conversational skill, yakni "mengikuti topik pembicaraan yang sudah dimulai oleh orang lain", menghasilkan skor minimal 1, skor maksimal 2, dengan skor mean empiris1,5. Skor mean empiris yang berada di bawah skor mean hipotetik menunjukkan bahwa kemampuan kelima partisipan dalam komponen ketujuh masih tergolong rendah.

Secara ringkas, gambaran hasil observasi conversational skill sebelum intervensi terangkum pada tabel 3 .
Tabel 3: Gambaran Komponen Conversational Skill Sebelum Intervensi

\begin{tabular}{|c|c|c|c|}
\hline $\begin{array}{c}\text { Conversational } \\
\text { Skill }\end{array}$ & Min. & Maks. & $\begin{array}{l}\text { Mean } \\
\text { Empi- } \\
\text { ris }\end{array}$ \\
\hline Kontak mata & 1 & 3 & 1.6 \\
\hline $\begin{array}{l}\text { Memulai } \\
\text { percakapan } \\
\text { dengan orang lain }\end{array}$ & 1 & 1.5 & 1.1 \\
\hline $\begin{array}{l}\text { Menjaga } \\
\text { percakapan } \\
\text { dengan bertanya }\end{array}$ & 1 & 2 & 1.3 \\
\hline $\begin{array}{l}\text { Menjaga } \\
\text { percakapan } \\
\text { dengan } \\
\text { memberikan } \\
\text { informasi faktual }\end{array}$ & 1 & 1.5 & 1.1 \\
\hline $\begin{array}{l}\text { Menjaga } \\
\text { percakapan } \\
\text { dengan } \\
\text { mengekspresikan } \\
\text { perasaan }\end{array}$ & 1 & 1.5 & 1.1 \\
\hline $\begin{array}{l}\text { Mengakhiri } \\
\text { pembicaraan }\end{array}$ & 1 & 1 & 1 \\
\hline $\begin{array}{l}\text { Mengikuti topik } \\
\text { pembicaraan } \\
\text { yang sudah } \\
\text { ditentukan oleh } \\
\text { orang lain. }\end{array}$ & 1 & 2 & 1.5 \\
\hline
\end{tabular}

\begin{tabular}{llcc}
\hline Skor total & 7 & 12.5 & 8.7 \\
\hline Skor rata-rata & 1 & 1.78 & 1.24 \\
\hline
\end{tabular}

Kelima subyek mendapatkan behavior therapy selama sekitar tiga minggu. Intervensi dilaksanakan sebanyak tujuh sesi, masing-masing sesi berlangsung selama kurang lebih 45 sampai 60 menit. Pelaksanaan intervensi adalah sebagai berikut:

Tabel 4: Pelaksanaan Intervensi

\begin{tabular}{lcc}
\hline Sesi & $\begin{array}{c}\text { Tujuan } \\
\text { sesi }\end{array}$ & Metode \\
\end{tabular}




\begin{tabular}{|c|c|c|c|}
\hline 1 & $\begin{array}{l}\text { Kontak } \\
\text { mata saat } \\
\text { berbicara \& } \\
\text { memulai } \\
\text { percakapan } \\
\text { dengan } \\
\text { orang lain }\end{array}$ & $\begin{array}{l}\text { Modeling, } \\
\text { shaping }\end{array}$ & $\begin{array}{l}\text { Senin, } \\
15 \text { Juni } \\
2015\end{array}$ \\
\hline 2 & $\begin{array}{l}\text { Menjaga } \\
\text { percakapan } \\
\text { dengan } \\
\text { bertanya }\end{array}$ & $\begin{array}{l}\text { Modeling, } \\
\text { shaping }\end{array}$ & $\begin{array}{l}\text { Rabu, } \\
\text { 17 Juni } \\
2015\end{array}$ \\
\hline 3 & $\begin{array}{l}\text { Menjaga } \\
\text { percakapan } \\
\text { dengan } \\
\text { memberi- } \\
\text { kan } \\
\text { informasi } \\
\text { faktual }\end{array}$ & $\begin{array}{l}\text { Modeling, } \\
\text { shaping }\end{array}$ & $\begin{array}{l}\text { Jumat, } \\
\text { 19 Juni } \\
2015\end{array}$ \\
\hline 4 & $\begin{array}{l}\text { Menjaga } \\
\text { percakapan } \\
\text { dengan } \\
\text { mengeks- } \\
\text { presikan } \\
\text { perasaan }\end{array}$ & $\begin{array}{l}\text { Modeling, } \\
\text { shaping }\end{array}$ & $\begin{array}{l}\text { Senin, } \\
22 \text { Juni } \\
2015\end{array}$ \\
\hline 5 & $\begin{array}{l}\text { Mengakhiri } \\
\text { pembicara- } \\
\text { an dengan } \\
\text { orang lain }\end{array}$ & $\begin{array}{l}\text { Modeling, } \\
\text { shaping }\end{array}$ & $\begin{array}{l}\text { Rabu, } \\
\text { 24 Juni } \\
2015\end{array}$ \\
\hline 6 & $\begin{array}{l}\text { Mengikuti } \\
\text { topik } \\
\text { pembicara- } \\
\text { an yang } \\
\text { sudah } \\
\text { ditentukan } \\
\text { oleh orang } \\
\text { lain }\end{array}$ & $\begin{array}{l}\text { Modeling, } \\
\text { shaping }\end{array}$ & $\begin{array}{l}\text { Jumat, } \\
26 \text { Juni } \\
2015\end{array}$ \\
\hline 7 & $\begin{array}{l}\text { Review dan } \\
\text { terminasi }\end{array}$ & $\begin{array}{l}\text { Modeling, } \\
\text { shaping }\end{array}$ & $\begin{array}{l}\text { Senin, } \\
29 \text { Juni } \\
2015\end{array}$ \\
\hline
\end{tabular}

Setelah sesi intervensi, peneliti kembali melakukan observasi untuk mengevaluasi efektivitas dari sesi intervensi. Observasi dilakukan 7 hari setelah sesi terakhir intervensi. Skor inter-rater reliability dari observasi adalah 0,63 . Hasil observasi setelah intervensi kemudian dibandingkan dengan hasil observasi sebelum intervensi.
Pada komponen kontak mata, hasil yang diperoleh dari kelima partisipan adalah skor minimal 2 dan skor maksimal 3, dengan mean empiris 2,8 dan mean hipotetis 3 . Hal ini menunjukkan bahwa kontak mata dari partisipan penelitian masih tergolong rendah. Meski demikian, terjadi peningkatan skor mean empiris dari 1,6 saat sebelum intervensi menjadi 2,8 saat setelah menjalani intervensi.

Pada komponen kedua dari conversational skill, yakni "memulai percakapan dengan orang lain", skor minimal di antara kelima partisipan adalah 1 dan skor maksimal adalah 3. Skor mean empiris dari kelima partisipan penelitian adalah 1,8 dan mean hipotetis 3 . Berdasarkan data tersebut, peneliti menyimpulkan bahwa pada kelima responden masih menunjukkan kemampuan yang rendah dalam memulai percakapan setelah menjalani intervensi, namun skor ini masih lebih tinggi dibandingkan skor mean empiris sebelum menjalani intervensi, yakni 1,1 .

Hasil observasi pada komponen ketiga, yaitu "menjaga percakapan dengan bertanya", menghasilkan skor minimal 2 dan skor maksimal 3; dengan skor mean empiris 2,2 dan mean hipotetis 3. Berdasarkan data tersebut, dapat disimpulkan bahwa skor ratarata kemampuan menjaga percakapan dengan bertanya pada kelima responden masih tergolong rendah.

Pada komponen keempat dari conversational skill, yakni "menjaga percakapan dengan memberikan informasi faktual", kelima subyek menunjukkan skor minimal 1 dan skor maksimal 2,5; dengan mean empiris 1,6 dengan skor mean hipotetis 3. Hal ini menunjukkan bahwa kelima partisipan memiliki kemampuan yang tergolong rendah untuk menjaga percakapan dengan memberikan informasi faktual setelah menjalani intervensi.

Komponen kelima dari conversational skill, yakni "menjaga percakapan dengan mengekspresikan perasaan", menghasilkan skor minimal 1,5 dan skor maksimal 2,5. Skor mean empiris 1,8 dan mean hipotetis 3, hal ini berarti kemampuan kelima partisipan untuk 
menjaga percakapan melalui mengekspresikan perasaan tergolong rendah.

Komponen keenam, yakni "mengakhiri pembicaraan" menghasilkan skor minimal 1 dan skor maksimal 2, dengan skor mean empiris 1,5. Skor mean empiris yang lebih kecil dibandingkan skor mean hipotetis dapat disimpulkan bahwa kemampuan kelima partisipan dalam mengakhiri pembicaraan setelah menjalani intervensi masih tergolong rendah.

Pada komponen terakhir, yaitu "mengikuti topik pembicaraan yang sudah ditentukan oleh orang lain" menunjukkan skor minimal 1,5 dan skor maksimal 3, serta skor mean empiris sebesar 2,3. Hal ini menunjukkan bahwa setelah menjalani intervensi, skor kelima partisipan dalam komponen ini masih tergolong rendah.

Gambaran conversational skill dari kelima partisipan setelah menjalani intervensi terangkum dalam tabel 5.

Tabel 5: Gambaran Komponen Conversational Skill Setelah Intervensi

\begin{tabular}{|c|c|c|c|}
\hline $\begin{array}{c}\text { Conversational } \\
\text { Skill }\end{array}$ & Min. & Maks. & $\begin{array}{c}\text { Mean } \\
\text { Empi- } \\
\text { ris }\end{array}$ \\
\hline Kontak mata & 2 & 3 & 2.8 \\
\hline $\begin{array}{l}\text { Memulai } \\
\text { percakapan } \\
\text { dengan orang lain }\end{array}$ & 1 & 3 & 1.8 \\
\hline $\begin{array}{l}\text { Menjaga } \\
\text { percakapan } \\
\text { dengan bertanya }\end{array}$ & 2 & 3 & 2.2 \\
\hline $\begin{array}{l}\text { Menjaga } \\
\text { percakapan } \\
\text { dengan } \\
\text { memberikan } \\
\text { informasi faktual }\end{array}$ & 1 & 2.5 & 1.6 \\
\hline $\begin{array}{l}\text { Menjaga } \\
\text { percakapan } \\
\text { dengan } \\
\text { mengekspresikan } \\
\text { perasaan }\end{array}$ & 1.5 & 2.5 & 1.8 \\
\hline $\begin{array}{l}\text { Mengakhiri } \\
\text { pembicaraan }\end{array}$ & 1 & 2 & 1.5 \\
\hline $\begin{array}{l}\text { Mengikuti topik } \\
\text { pembicaraan }\end{array}$ & 1.5 & 3 & 2.3 \\
\hline
\end{tabular}

yang sudah

ditentukan oleh

orang lain.

\begin{tabular}{lccc}
\hline Skor total & 10 & 19 & 14 \\
\hline Skor rata-rata & 1.43 & 2.71 & 2 \\
\hline
\end{tabular}

Meskipun rata-rata skor dari ketujuh komponen conversational skill dari kelima partisipan setelah menjalani intervensi masih tergolong rendah, namun terjadi peningkatan rata-rata skor conversational skill setelah menjalani intervensi, yang dapat dilihat pada tabel 6 .

Tabel 6: Perbandingan Conversational Skill Sebelum dan Setelah Intervensi

\section{Conversational Skill}

Sebelum Sesudah

Kontak mata

Memulai

percakapan dengan

orang lain

Menjaga

percakapan dengan

bertanya

Menjaga

percakapan dengan

memberikan

informasi faktual

Menjaga

percakapan dengan

mengekspresikan

perasaan

Mengakhiri

pembicaraan

Mengikuti topik

pembicaraan yang

sudah ditentukan

oleh orang lain.
1.6

2.8

1.1

\begin{tabular}{lcc}
\hline Skor total & 8.7 & 14 \\
\hline Skor rata-rata & 1.24 & 2 \\
\hline
\end{tabular}

$$
\text { Perbandingan }
$$

skor total conversational skill dari kelima partisipan 
penelitian sebelum dan setelah menjalani intervensi terangkum dalam tabel 7.

Tabel 7: Perbandingan Conversational Skill dari Kelima Subyek Sebelum dan Setelah Menjalani Intervensi

\begin{tabular}{ccc}
\hline Partisipan & Sebelum & Sesudah \\
\hline HW & 9.5 & 16 \\
APN & 9 & 14.5 \\
RD & 7.5 & 12 \\
CH & 10.5 & 17.4 \\
AR & 7 & 10 \\
\hline
\end{tabular}

Dengan menggunakan pengujian one sample $K S$ test, didapatkan hasil bahwa data yang diperoleh oleh peneliti berdistribusi normal baik untuk data pada kelompok sebelum dan kelompok sesudah. Setelah melakukan uji asumsi dan data normal, peneliti menggunakan paired sample t-test untuk uji non-parametrik. Berdasarkan hasil paired sample t-test, diperoleh hasil signifikansi $\mathrm{p}=0,002<0,05$; sehingga peneliti menyimpulkan terdapat perbedaan skor conversational skill antara sebelum dan sesudah treatment secara signifikan.

Kemudian, masing-masing komponen dari conversational skill diuji dengan paired sample t-test untuk mengetahui perbedaan skor dari masingmasing komponen antara sebelum dan sesudah treatment.

Pengujian t-test pada komponen pertama, yakni kontak mata, menunjukkan signifikansi $\mathrm{p}=0,024<0,05$. Hal ini berarti terdapat perbedaan yang signifikan pada kontak mata subyek sebelum dan sesudah mendapatkan treatment.

Pada komponen kedua, yakni memulai percakapan dengan orang lain, hasil pengujian t-test menunjukkan skor signifikansi $\mathrm{p}=0,080>0,05$. Hal ini menunjukkan bahwa tidak ada perbedaan yang signifikan pada kemampuan subyek untuk memulai percakapan sebelum dan sesudah menjalani intervensi atau treatment.

Pada komponen ketiga, menjaga percakapan dengan bertanya, hasil pengujian t-test menunjukkan skor signifikansi $\mathrm{p}=$ $0,001<0,05$. Hal ini berarti ada perbedaan yang signifikan antara sebelum dan sesudah menjalani treatment pada komponen menjaga percakapan dengan bertanya.

Komponen keempat, yakni menjaga percakapan dengan memberikan informasi faktual, diperoleh hasil signifikansi $\mathrm{p}=$ $0,070>0,05$. Hal ini berarti tidak ada perbedaan yang signifikan pada komponen tersebut antara sebelum dan sesudah mendapatkan treatment.

Hasil pengujian paired sample t-test pada komponen kelima, yakni menjaga percakapan dengan menyatakan perasaan, memeroleh skor signifikansi $p=0,052>0,05$. Hal ini berarti tidak ada perbedaan yang signifikan di antara sebelum dan sesudah treatment.

Pada komponen keenam, yakni mengakhiri percakapan, diperoleh skor signifikansi $\mathrm{p}=0,089>0,05$. Hal ini menunjukkan bahwa tidak ada perbedaan yang signifikan pada kemampuan subyek untuk mengakhiri percakapan antara sebelum dan sesudah menjalani treatment.

Komponen terakhir, yakni mengikuti percakapan yang sudah dimulai oleh orang lain, diperoleh skor signifikansi $\mathrm{p}$ $=0,03<0,05$. Hal ini menunjukkan bahwa terdapat perbedaan yang signfikan antara skor komponen tersebut antara sebelum dan sesudah menjalani intervensi atau treatment.

Ringkasan dari hasil pengujian di atas terangkum dalam tabel 8 .

Tabel 8. Hasil Uji Paired-Sample T-Test

\begin{tabular}{|c|c|c|c|}
\hline Komponen & $\begin{array}{c}\text { Mean } \\
\text { Sebe- } \\
\text { lum }\end{array}$ & $\begin{array}{c}\text { Mean } \\
\text { Sesu- } \\
\text { dah }\end{array}$ & $\begin{array}{l}\text { Signifi- } \\
\text { kansi } \\
\text { (p) }\end{array}$ \\
\hline Kontak mata & 1.6 & 2.8 & 0.024 \\
\hline $\begin{array}{l}\text { Memulai } \\
\text { percakapan }\end{array}$ & 1.1 & 1.8 & 0.080 \\
\hline $\begin{array}{l}\text { Mempertaha } \\
\text { nkan } \\
\text { percakapan } \\
\text { dengan } \\
\text { bertanya }\end{array}$ & 1.3 & 2.2 & 0.001 \\
\hline $\begin{array}{l}\text { Mempertaha } \\
\text { nkan } \\
\text { percakapan } \\
\text { dengan }\end{array}$ & 1.1 & 2.0 & 0.070 \\
\hline
\end{tabular}


memberikan

info factual

Mempertaha

nkan

percakapan

dengan

$\begin{array}{lll}1.1 & 1.8 & 0.052\end{array}$

mengungkap

kan perasaan

Mengakhiri

percakapan

$\begin{array}{lll}1.0 & 1.5 & 0.089\end{array}$

Mengikuti

topik

pembicara-

an yang

sudah

0.003

ditentukan

oleh orang

lain

\section{Total}

(Conversatio

$8.7 \quad 13.98$

0.002

nal Skill)

\section{SIMPULAN DAN SARAN}

Berdasarkan hasil pengujian paired sample t-test, ditemukan perbedaan yang signifikan pada skor conversational skill antara sebelum dan sesudah menjalani group behavior therapy, sehingga dapat disimpulkan bahwa group behavior therapy dapat dipertimbangkan sebagai metode yang efektif untuk meningkatkan conversational skill pada pasien schizophrenia tipe residual.

Komponen-komponen conversational skill yang mengalami peningkatan secara signifikan setelah menjalani group behavior therapy adalah kontak mata, mempertahankan percakapan dengan bertanya, dan mengikuti topik pembicaraan yang sudah dimulai oleh orang lain. Sedangkan komponen lainnya, seperti mempertahankan percakapan dengan memberikan informasi faktual, mengekspresikan pertanyaan, memulai percakapan, dan mengakhiri percakapan; meskipun mengalami peningkatan skor, namun tidak signifikan.

Dalam penelitian ini, role play (melalui modeling) dan positive reinforcement menjadi dua teknik utama yang digunakan untuk mengintervensi conversational skill dari subyek. Hal ini sesuai dengan penemuan dari Padmavathi, Lalitha, dan Parthasarathy (2013) bahwa role play merupakan metode yang efektif untuk meningkatkan conversational skill dari pasien schizophrenia.

Meski demikian, terdapat beberapa keterbatasan dalam penelitian ini, yakni subyek yang terlibat dalam penelitian ini berjumlah sedikit dan kurang homogen dari segi usia. Selain itu, jumlah sesi terapi yang kurang banyak, yakni hanya 7 (tujuh) sesi dianggap terlalu singkat sehingga kurang memberikan hasil yang maksimal. Riset yang dilakukan oleh Seo JM et al (dalam Padmavathi, Lalitha, dan Parthasarathy; 2013) membutuhkan 16 sesi dalam memberikan pelatihan conversational skill terhadap pasien schizophrenia.

Untuk penelitian selanjutnya, peneliti menyarankan agar subyek yang dilibatkan dalam penelitian bisa lebih banyak lagi. Selain itu, komponenkomponen social skills lainnya, yakni relational skill dan assertiveness skill juga dapat diteliti, guna mendapatkan teknik yang tepat untuk melatih keseluruhan social skills pada penderita schizophrenia tipe residual, agar mereka dapat segera kembali ke masyarakat dengan baik seperti sedia kala. Selain itu, jumlah sesi terapi juga perlu diperbanyak guna memaksimalkan manfaat dari terapi.

\section{DAFTAR PUSTAKA}

Arif, I.S. (2006). Skizofrenia: Memahami dinamika keluarga pasien. Bandung: Refika Aditama.

Bellack, A.S., Mueser, K.T., Gingerich, S., \& Agresta, J. (2004). Social skills training for schizophrenia: A step-bystep guide $\left(2^{\text {nd }}\right.$ ed.). NY: Guilford Press.

Barlow, D.H., \& Durand, V.M. (2012). Abnormal psychology: An integrative approach. NY: McGraw-Hill.

Feist, J., Feist, G.J., Roberts, T.A. (2013). Theories of personality ( $8^{\text {th }} \mathrm{ed}$.). NY: McGraw-Hill 
Hafner, H., \& Heiden, W. (1997). Epidemiology of schizophrenia. Canadian Journal of Psychiatry, 41(2), h.139-151. DOI: 10.1007/9783-642-71765-9_6

Halgin, R.P., \& Whitbourne, S.K. (2009). Abnormal psychology: Clinical perspectives on psychological disorders (6 ${ }^{\text {th }}$ ed.). NY:McGraw-Hill.

Heinssen RK, Liberman RP, Kopelowicz A. (2000). Psychosocial skill training for schizophrenia: Lessons from the laboratory. Schizophrenia Bulletin, 26, pp.21-46.

Kring, A.M., Johnson, S.L., Davison, G.C., \& Neale, J. (2012). Abnormal psychology $\left(12^{\text {th }}\right.$ ed.). NY: McGrawHill.

McGrath, J., Saha, S., Chant, D., Welham, J. (2008). Schizophrenia: A concise overview of incidence, prevalence, and mortality. Epidemiologic Reviews, 30, h.67-76. DOI: 10.1093/epirev/mxn001

National Institute of Mental Health. (2011). Schizophrenia. Diunduh dari http://www.nimh.nih.gov/health/publi cations/schizophrenia/completeindex.shtml
Padmavathi, N., Lalitha, K., Parthasarathy, R. (2013). Effectiveness of conversational skill training of patients with schizophrenia. Journal of Krishna Institute of Medical Sciences University, 2(2), pp.42-47.

Saha, S., Chant, D., Welham, J., McGrath, J. (2005). A systematic review of the prevalence of schizophrenia. Plos Medicine, 2(5), h.413-433. DOI: 10.1371/journal.pmed.0020141.

Sellwood, W., Thomas, C.S., Tarrier, N., Jones, S., Clewes, J., James, A., Welford, M., Palmer, J., McCarthy, E. (1999). A randomised controlled trial of home-based rehabilitation versus outpatient-based rehabilitation for patients suffering from chronic schizophrenia. Social Psychiatry Epidemiology, 34, pp.250-253.

Trull, T.J. (2005). Clinical psychology $\left(7^{\text {th }}\right.$ ed.). NY: Cengage Learning. 
